\title{
Association of complete blood cell counts with metabolic syndrome in an elderly population
}

Peng-Fei Li ${ }^{1}$, Jin-Shuen Chen ${ }^{2}$, Jin-Biou Chang ${ }^{3}$, Hsiao-Wen Chang ${ }^{1}$, Chung-Ze Wu ${ }^{4}$, Tsung-Ju Chuang ${ }^{1}$, Chia-Luen Huang ${ }^{1}$, Dee Pei ${ }^{5}$, Chang-Hsun Hsieh ${ }^{1 * \dagger}$ and Yen-Lin Chen ${ }^{6 *+}$

\begin{abstract}
Background: Metabolic syndrome's (MetS) role in predicting cardiovascular diseases and diabetes has been confirmed in many large cohort studies. Nontraditionally, hematogram components are significantly related to MetS in many different age groups. However, little is known about its role among the elderly.
\end{abstract}

Methods: We enrolled 18,907 subjects over the age of 65 years who underwent regular health examinations. They were divided into three groups according to age: young old ( $\mathrm{YO}: \geq 65$ and $<74$ years old), old old (OO: $\geq 75$ and $<84$ years old), and oldest old (ODO: $\geq 85$ years old). The MetS components were determined, and correlations between MetS and hematogram components were evaluated using Pearson and multivariate linear regression analyses. The hematogram components were the independent variables evaluated separately against the dependent variable (MetS components).

Results: While SBP and HDL-C increased, most other MetS and hematogram parameters decreased in men with age. Fewer significant differences were noted among the women. In the $\mathrm{YO}$ and $\mathrm{OO}$ groups for both genders, the subjects with MetS had higher WBC and Hb. None of the hematogram components were different for subjects with or without MetS in the ODO group. Multiple regression results show that most of the relationships between hematogram and MetS components disappeared in the ODO groups. The WBC levels were mainly correlated with WC and TG. At the same time, Hb was associated with BP, FPG, and LDL-C. Compared to WBC and Hb, PLT was least related to MetS, except in the cases of LDL-C and TG. Among the MetS components, BMI, LDL-C, and TG were consistently related to all the hematogram components in $\mathrm{YO}$ and $\mathrm{OO}$ men. However, only TG had the same consistency among $\mathrm{YO}$ and $\mathrm{OO}$ women.

Conclusions: This study's three major findings are as follows: WBC and Hb are associated with MetS, even among the $\mathrm{YO}$ and $\mathrm{OO}$ groups, regardless of gender; among the three hematogram components, $\mathrm{Hb}$ had the strongest and PLT had the weakest correlation with MetS; and TG is not the only component with relatively higher $r$ values, and it is related to all hematogram components.

Keywords: Metabolic syndrome components, Hematogram parameters, Elderly population

\footnotetext{
*Correspondence: ; anthonypatho@gmail.com

${ }^{\dagger}$ Equal contributors

'Division of Endocrinology and Metabolism, Department of Internal

Medicine, Tri-Service General Hospital, National Defense Medical Center,

Taipei, Taiwan

${ }^{6}$ Department of Pathology, Cardinal Tien Hospital, School of Medicine, Fu-Jen

Catholic University, New Taipei City, Taiwan

Full list of author information is available at the end of the article
} 


\section{Background}

Cardiovascular diseases (CVD) and diabetes have always been among the top five causes of death in Taiwan, as well as in many other countries. They cause tremendous burden, not only for the affected individuals but also for society as a whole. Since the prevalence of obesity has simultaneously increased, it is considered to be a main cause of this phenomenon [1].

Early in 1964, the clustering of hyperglycemia, hyperlipidemia, hypertension, and central obesity was found to be related to the aforementioned two diseases. In 1999 , to perform early detection of the subjects most at risk for these diseases, the World Health Organization (WHO) proposed the term "metabolic syndrome (MetS)" to denote this clustering. Subsequently, many large-scale studies were performed and repeatedly confirmed the predictive power of MetS. At the same time, several other abnormalities, such as microalbuminuria, inflammation markers, and adipocytokines were found to have strong correlations with CVD and diabetes [2, 3]. Contrary to the MetS components, these markers are considered to be "non-traditional components" [4-8]. For example, white blood cell (WBC) count was first found to be associated with MetS by Nagasawa et al. This is not completely surprising, since WBC itself is a marker of inflammation [9]. What is more interesting is that hemoglobin $(\mathrm{Hb})$, platelet (PLT) count, and mean platelet volume (MPV) all had similar relationships. This evidence strongly implies an association between hematogram components and chronic inflammation [10-14]. Although a number of studies have been published with younger adults [4-12], little is known about the similar relationships between hematogram and MetS components among the elderly.

Due to the National Health Insurance Policy, modern Taiwanese have a longer life expectancy than ever before. At present, $14 \%$ of the population is over 65 years old, which marks this as an "aging society". Additionally, the increased incidence of MetS among the elderly will inevitably lead to more CVD and T2D. This is a major issue that will have to be dealt with by health providers and policy makers alike. Since a hematogram is a readily available, inexpensive test that can be performed even in basic medical units, it would be a very good tool for detecting subjects who are at high risk of developing MetS.

It is generally agreed that health problems may vary according to age group, and this is especially true among the elderly. Due to these different relationships between risk factors and outcomes, previous studies have further classified the elderly into three groups: young old (YO: $\geq 65$ and $<75$ ), old old (OO: $\geq 75$ and $<85$ ), and oldest old $(\mathrm{ODO} \geq 85)[15,16]$. In this cross-sectional study, our purpose was first to demonstrate the demographic information of the hematogram parameters and further analyze their relationships with MetS components among the three elderly groups. It is expected that the present study's results will enable a greater understanding of the roles of MetS hematogram components.

\section{Method \\ Study population}

MJ Health Screening Centers are privately owned clinics located throughout Taiwan that only provide regular health examinations to their members. The participants in this study were enrolled when they underwent their routine health checkups at this clinic. Anonymity was ensured for, and informed consent was obtained from, all study participants. The study protocol was approved by the institutional review board of the MJ Health Screening Center, and the data obtained were used for research purposes only. We randomly selected 36,169 subjects who were over 65 years old during the sampling period, from 1999 to 2008. We excluded 3347 subjects who visited only once during the sampling period. We used more stringent exclusion criteria to make our results more reliable. We excluded subjects with past histories of hypertension, T2D, hyperlipidemia, cardiovascular events, renal function impairment (plasma creatinine $>1.2 \mathrm{mg} / \mathrm{dl}$ ), established bone marrow or hematology diseases, established malignancy or gastrointestinal tract bleeding, and recent infectious disease. Those who were taking medications (such as antibiotics, immune suppression agents, steroids, hormonal treatment, etc.) known to affect complete blood cell counts or MetS components were also excluded $(n=11,562)$. Data from 2353 more subjects who had missing values for MetS components, hematogram components, and other related data were removed from the analysis, leaving a total of 18,907 eligible subjects. To further study the different elderly groups, we grouped subjects according to their ages as YO, OO, and ODO groups [17].

\section{Anthropometric measurements and general data}

A standard checkup protocol was followed at the MJ clinic. The senior nursing staff used a questionnaire to obtain the subject's medical history, including information on any current medications. Then, complete physical examinations were performed. Waist circumference (WC) was measured horizontally at the level of the natural waist, which was identified as the level at the hollow molding of the laterally concave trunk. Body mass index (BMI) was calculated as a subject's body weight $(\mathrm{kg}) \mathrm{di}-$ vided by the square of the subject's height $(\mathrm{m})$. Both systolic blood pressure (SBP) and diastolic blood pressure (DBP) were measured by the nursing staff using a standard mercury sphygmomanometer that was fitted on the right arm of each seated subject. Laboratory measurements, including blood sample analysis, were 
conducted after the subjects fasted for $10 \mathrm{~h}$. The blood samples were drawn from the antecubital vein for biochemical analysis. Plasma was separated from the blood within $1 \mathrm{~h}$, it was stored at $-30{ }^{\circ} \mathrm{C}$, and then it was analyzed for both FPG and lipid profiles. FPG was detected using a glucose oxidase method (YSI 203 glucose analyzer, Scientific Division, Yellow Springs Instruments, Yellow Springs, OH). Total cholesterol and triglycerides (TG) were measured using the dry, multilayer analytical slide method in the Fuji Dri-Chem 3000 analyzer (Fuji Photo Film, Minato-Ku, Tokyo, Japan). Serum highdensity lipoprotein cholesterol (HDL-C) and low-density lipoprotein cholesterol (LDL-C) concentrations were analyzed using an enzymatic cholesterol assay following dextran sulfate precipitation. WBC, $\mathrm{Hb}$, and PLT were measured with an Abbott Cell Dyn 3000 hematology analyzer (Abbott Laboratories, Abbott Park, IL, USA).

\section{Definition of metabolic syndrome}

We used a slightly modified version of the 2009 harmonized MetS criteria [18]. WC was $\geq 90$ and $80 \mathrm{~cm}$ in Taiwanese men and women, respectively [19]. The other four criteria were the same; namely, SBP $\geq 130 \mathrm{mmHg}$ or DBP $\geq 85 \mathrm{mmHg}, \mathrm{TG} \geq 150 \mathrm{mg} / \mathrm{dL}, \quad F P G \geq 100 \mathrm{mg} / \mathrm{dL}$, and $\mathrm{HDL} \leq 40$ and $50 \mathrm{mg} / \mathrm{dL}$ for men and women. Subjects had to meet at least three criteria to be diagnosed as MetS.

\section{Statistical analysis}

The data in this study are presented as mean \pm standard deviation. All data were tested for normal distribution with the Kolmogorov-Smirnov test, and the homogeneity of their variances was assessed with Levene's test. A $t$-test was used to evaluate the differences between two groups. When comparing the differences between three groups, a one-way ANOVA was used. For post hoc comparisons, the Bonferroni test was applied. Correlations between MetS components and hematogram were evaluated using the Pearson correlation. Multivariate linear regression analysis was performed to confirm if hematogram was independently related to MetS components. A $p$-value (two-sided) $<0.05$ was considered to be significant. All statistical analyses were performed using SPSS 18.0 software (SPSS Inc., Chicago, IL).

\section{Results}

There were 18,907 subjects enrolled in this study. Table 1 shows the demographic data for the different groups and allows an examination of the effects of aging on the observational parameters. In general, BMI, DBP, TC, LDL-C, TG, Hb, and PLT became significantly lower, and SBP and HDL-C became significantly higher in men as they aged. As for women, fewer significant differences were noted.
Table 1 Demographic data for the different elderly groups

\begin{tabular}{|c|c|c|c|c|}
\hline & Young-old & Old-old & Oldest-old & $P$ value \\
\hline \multicolumn{5}{|l|}{ Male } \\
\hline$n$ & 7648 & 1963 & 121 & \\
\hline Age (years) & $68.7 \pm 2.8$ & $77.8 \pm 2.5$ & $87.0 \pm 2.2$ & $<0.001$ \\
\hline WC (cm) & $85.1 \pm 9.1$ & $84.9 \pm 9.6$ & $84.6 \pm 10.1$ & 0.492 \\
\hline BMI $\left(\mathrm{kg} / \mathrm{m}^{2}\right)$ & $23.8 \pm 3.1$ & $23.2 \pm 3.2$ & $22.8 \pm 3.2$ & $<0.001$ \\
\hline SBP $(\mathrm{mmHg})$ & $135.6 \pm 20.3$ & $139.3 \pm 20.2$ & $139.5 \pm 22.4$ & $<0.001$ \\
\hline $\mathrm{DBP}(\mathrm{mmHg})$ & $77.3 \pm 11.7$ & $75.2 \pm 11.9$ & $73.4 \pm 12.9$ & $<0.001$ \\
\hline $\mathrm{FPG}(\mathrm{mg} / \mathrm{dl})$ & $109.8 \pm 32.5$ & $110.4 \pm 32.1$ & $105.5 \pm 17.9$ & 0.238 \\
\hline $\mathrm{TC}(\mathrm{mg} / \mathrm{dl})$ & $199.8 \pm 36.4$ & $194.3 \pm 35.4$ & $190.8 \pm 35.0$ & $<0.001$ \\
\hline $\mathrm{HDL}-\mathrm{C}(\mathrm{mg} / \mathrm{dl})$ & $49.3 \pm 13.9$ & $50.4 \pm 14.7$ & $51.7 \pm 16.0$ & 0.003 \\
\hline LDL-C (mg/dl) & $125.0 \pm 32.7$ & $119.3 \pm 31.3$ & $116.9 \pm 30.2$ & $<0.001$ \\
\hline $\mathrm{TG}(\mathrm{mg} / \mathrm{dl})$ & $127.7 \pm 68.1$ & $123.1 \pm 65.3$ & $110.9 \pm 50.6$ & 0.001 \\
\hline LogTg & $2.1 \pm 0.2$ & $2.0 \pm 0.2$ & $2.0 \pm 0.2$ & $<0.001$ \\
\hline WBC (x10 $3 / \mathrm{uL})$ & $6.5 \pm 1.8$ & $6.5 \pm 1.9$ & $6.7 \pm 1.8$ & 0.461 \\
\hline Hemoglobin (g/dl) & $14.7 \pm 1.3$ & $14.3 \pm 1.4$ & $13.8 \pm 1.6$ & $<0.001$ \\
\hline Platelet ( $\left.\times 10^{3} / \mathrm{uL}\right)$ & $213.1 \pm 55.7$ & $202.9 \pm 57.0$ & $197.6 \pm 52.5$ & $<0.001$ \\
\hline \multicolumn{5}{|l|}{ Female } \\
\hline$n$ & 7521 & 1573 & 81 & \\
\hline Age (years) & $68.5 \pm 2.7$ & $77.8 \pm 2.6$ & $86.8 \pm 2.0$ & $<0.001$ \\
\hline$W C(\mathrm{~cm})$ & $80.1 \pm 8.9$ & $82.1 \pm 9.6$ & $83.5 \pm 9.1$ & $<0.001$ \\
\hline BMI $\left(\mathrm{kg} / \mathrm{m}^{2}\right)$ & $24.5 \pm 3.6$ & $24.0 \pm 3.7$ & $23.5 \pm 4.0$ & $<0.001$ \\
\hline $\mathrm{SBP}(\mathrm{mmHg})$ & $139.9 \pm 20.8$ & $145.9 \pm 21.2$ & $149.5 \pm 19.4$ & $<0.001$ \\
\hline $\mathrm{DBP}(\mathrm{mmHg})$ & $76.8 \pm 11.8$ & $76.2 \pm 12.3$ & $76.8 \pm 11.5$ & 0.230 \\
\hline FPG (mg/dl) & $110.0 \pm 33.5$ & $110.1 \pm 29.6$ & $109.4 \pm 26.7$ & 0.976 \\
\hline TC (mg/dl) & $214.3 \pm 38.5$ & $210.5 \pm 36.9$ & $212.7 \pm 42.4$ & 0.002 \\
\hline $\mathrm{HDL}-\mathrm{C}(\mathrm{mg} / \mathrm{dl})$ & $57.0 \pm 15.1$ & $57.0 \pm 15.8$ & $56.8 \pm 16.6$ & 0.976 \\
\hline LDL-C (mg/dl) & $129.6 \pm 34.5$ & $125.8 \pm 32.5$ & $127.3 \pm 37.6$ & $<0.001$ \\
\hline TG $(\mathrm{mg} / \mathrm{dl})$ & $138.2 \pm 69.2$ & $139.5 \pm 68.5$ & $143.0 \pm 65.9$ & 0.668 \\
\hline $\log T g$ & $2.1 \pm 0.2$ & $2.1 \pm 0.2$ & $2.1 \pm 0.2$ & 0.381 \\
\hline WBC (x10 $3 / \mathrm{uL})$ & $6.2 \pm 1.7$ & $6.3 \pm 1.8$ & $6.7 \pm 2.0$ & 0.002 \\
\hline Hemoglobin (g/dl) & $13.3 \pm 1.1$ & $13.0 \pm 1.3$ & $12.9 \pm 1.3$ & $<0.001$ \\
\hline Platelet $\left(\times 10^{3} / \mathrm{uL}\right)$ & $231.2 \pm 56.5$ & $226.2 \pm 59.4$ & $213.1 \pm 59.4$ & $<0.001$ \\
\hline
\end{tabular}

$B M I$ body mass index, WC waist circumference, $S B P$ systolic blood pressure, $D B P$ diastolic blood pressure, FPG fasting plasma glucose, TC total cholesterol, $H D L-C$ high-density lipoprotein cholesterol, $L D L-C$ low-density lipoprotein cholesterol, TG triglyceride, LogTG log transformed triglyceride, WBC white blood cell count

Data are shown as mean \pm SD

$\mathrm{Hb}$ and PLT were lower, while WC, SBP, and WBC were higher for the ODO group of women.

Table 2 shows the differences of hematogram components in subjects with and without MetS. In the YO and OO groups for both sexes, not surprisingly the subjects who had MetS had higher WBC and Hb. PLT levels were not higher for the subjects with MetS, except for the $\mathrm{YO}$ group in females. Interestingly, none of the 
Table 2 Differences in hematogram components between subjects with or without metabolic syndrome

\begin{tabular}{|c|c|c|c|c|c|c|c|c|c|}
\hline & \multicolumn{3}{|l|}{ Young-old } & \multicolumn{3}{|l|}{ Old-old } & \multicolumn{3}{|l|}{ Oldest-old } \\
\hline & MetS(-) & MetS(+) & $p$ value & MetS(-) & MetS(+) & $p$ value & MetS(-) & MetS(+) & $p$ value \\
\hline \multicolumn{10}{|l|}{ Male } \\
\hline$n$ & 5049 & 2599 & & 1273 & 690 & & 83 & 38 & \\
\hline WBC & $6.3 \pm 1.7$ & $6.8 \pm 1.8$ & $<0.001$ & $6.2 \pm 1.8$ & $6.9 \pm 2.0$ & $<0.001$ & $6.6 \pm 2.0$ & $6.9 \pm 1.5$ & 0.393 \\
\hline $\mathrm{Hb}$ & $14.6 \pm 1.3$ & $15.0 \pm 1.3$ & $<0.001$ & $14.1 \pm 1.4$ & $14.5 \pm 1.5$ & $<0.001$ & $13.6 \pm 1.6$ & $14.1 \pm 1.5$ & 0.105 \\
\hline PLT & $212.5 \pm 55.8$ & $214.3 \pm 55.5$ & 0.168 & $201.4 \pm 58.7$ & $205.7 \pm 53.7$ & 0.111 & $198.0 \pm 53.1$ & $196.9 \pm 51.7$ & 0.914 \\
\hline \multicolumn{10}{|c|}{ Female } \\
\hline$n$ & 4004 & 3517 & & 718 & 855 & & 30 & 51 & \\
\hline WBC & $5.9 \pm 1.6$ & $6.6 \pm 1.8$ & $<0.001$ & $5.9 \pm 1.7$ & $6.6 \pm 1.9$ & $<0.001$ & $6.3 \pm 2.0$ & $6.9 \pm 2.0$ & 0.203 \\
\hline $\mathrm{Hb}$ & $13.2 \pm 1.1$ & $13.4 \pm 1.2$ & $<0.001$ & $12.8 \pm 1.2$ & $13.2 \pm 1.3$ & $<0.001$ & $12.6 \pm 1.3$ & $13.0 \pm 1.2$ & 0.107 \\
\hline PLT & $226.3 \pm 55.3$ & $236.8 \pm 57.4$ & $<0.001$ & $223.0 \pm 58.9$ & $228.9 \pm 59.6$ & 0.050 & $202.8 \pm 53.0$ & $219.2 \pm 62.5$ & 0.233 \\
\hline
\end{tabular}

MetS(-) without metabolic syndrome, MetS(+) with metabolic syndrome, WBC white blood cell count, Hb hemoglobin, PLT platelet count Data are shown as mean \pm SD

hematogram components were different for the subjects with and without MetS in the ODO group.

The results of the Pearson's correlation and multiple regression are shown in Tables 3 and 4, respectively. In multiple regression, the hematogram components (WBC, $\mathrm{Hb}$, and PLT) were taken as independent variables and were evaluated separately against the dependent variable (MetS components). Using this method, the effects from the individual hematogram components could be adjusted. In general, most of the relationships between hematogram and MetS disappeared in the ODO groups. The WBC levels were mainly correlated with WC and TG. At the

Table 3 Univariate analysis of hematogram and metabolic syndrome components

\begin{tabular}{|c|c|c|c|c|c|c|c|c|c|}
\hline & \multicolumn{3}{|c|}{ Young-old } & \multicolumn{3}{|l|}{ Old-old } & \multicolumn{3}{|c|}{ Oldest-old } \\
\hline & $\overline{W B C}$ & $\mathrm{Hb}$ & PLT & $\overline{W B C}$ & $\mathrm{Hb}$ & PLT & WBC & $\mathrm{Hb}$ & PLT \\
\hline \multicolumn{10}{|l|}{ Male } \\
\hline Age & NS & -0.091 & -0.062 & NS & -0.108 & NS & NS & NS & NS \\
\hline $\mathrm{BMI}$ & 0.096 & 0.198 & -0.044 & 0.060 & 0.221 & -0.097 & NS & 0.259 & NS \\
\hline WC & 0.152 & 0.195 & NS & 0.113 & 0.215 & NS & NS & 0.219 & NS \\
\hline SBP & 0.079 & 0.084 & NS & 0.049 & 0.090 & NS & NS & 0.263 & NS \\
\hline $\mathrm{DBP}$ & 0.049 & 0.170 & NS & NS & 0.195 & NS & NS & 0.396 & NS \\
\hline FPG & 0.072 & 0.064 & 0.025 & NS & 0.062 & NS & NS & NS & NS \\
\hline $\mathrm{HDL}-\mathrm{C}$ & -0.129 & NS & NS & -0.171 & -0.063 & -0.051 & -0.218 & NS & NS \\
\hline LDL-C & 0.084 & 0.169 & 0.091 & 0.078 & 0.212 & 0.084 & NS & 0.240 & NS \\
\hline $\mathrm{TG}$ & 0.185 & 0.158 & 0.109 & 0.218 & 0.175 & 0.118 & NS & 0.202 & NS \\
\hline \multicolumn{10}{|l|}{ Female } \\
\hline Age & 0.040 & -0.068 & -0.038 & NS & NS & NS & NS & -0.267 & NS \\
\hline $\mathrm{BMI}$ & 0.173 & 0.130 & NS & 0.151 & 0.156 & NS & NS & 0.226 & NS \\
\hline WC & 0.205 & 0.099 & 0.039 & 0.193 & 0.120 & NS & NS & 0.257 & NS \\
\hline SBP & 0.104 & 0.062 & NS & 0.073 & 0.062 & NS & NS & NS & NS \\
\hline DBP & 0.070 & 0.157 & NS & 0.083 & 0.192 & NS & NS & NS & -0.325 \\
\hline FPG & 0.122 & 0.122 & 0.034 & 0.111 & 0.085 & 0.056 & NS & NS & NS \\
\hline $\mathrm{HDL}-\mathrm{C}$ & -0.113 & 0.023 & -0.026 & -0.126 & NS & NS & -0.308 & NS & NS \\
\hline LDL-C & 0.046 & 0.131 & 0.117 & 0.054 & 0.146 & 0.057 & NS & 0.221 & NS \\
\hline TG & 0.213 & 0.121 & 0.142 & 0.179 & 0.125 & 0.112 & 0.274 & NS & NS \\
\hline
\end{tabular}

$B M I$ body mass index, WC waist circumference, SBP systolic blood pressure, DBPdiastolic blood pressure, FPG fasting plasma glucose, $T C$ total cholesterol, $H D L-C$ high-density lipoprotein cholesterol, $L D L-C$ low-density lipoprotein cholesterol, TG triglyceride, NS non-significant

Data are shown as the $r$ value when $p$ value $<0.05$ 
Table 4 Multivariate analysis of hematogram and metabolic syndrome components

\begin{tabular}{|c|c|c|c|c|c|c|c|c|c|}
\hline & \multicolumn{3}{|c|}{ Young-old } & \multicolumn{3}{|l|}{ Old-old } & \multicolumn{3}{|c|}{ Oldest-old } \\
\hline & WBC & $\mathrm{Hb}$ & PLT & WBC & $\mathrm{Hb}$ & PLT & WBC & $\mathrm{Hb}$ & PLT \\
\hline \multicolumn{10}{|l|}{ Male } \\
\hline Age & --- & --- & -0.060 & --- & -0.077 & --- & --- & --- & --- \\
\hline BMI & 0.086 & 0.092 & -0.091 & 0.091 & 0.131 & -0.166 & --- & NS & --. \\
\hline WC & 0.223 & 0.058 & --- & 0.172 & NS & --- & --- & NS & --- \\
\hline SBP & 0.074 & -0.112 & --- & NS & -0.085 & --- & --- & NS & --- \\
\hline DBP & NS & 0.206 & --- & --- & 0.208 & --- & --- & 0.398 & --- \\
\hline FPG & 0.029 & 0.037 & NS & --- & NS & --- & --- & --- & --- \\
\hline HDL-C & -0.053 & --- & --- & -0.103 & 0.066 & -0.052 & -0.218 & --- & --- \\
\hline LDL-C & 0.074 & 0.148 & 0.090 & 0.057 & 0.169 & 0.083 & --- & NS & --- \\
\hline TG & 0.137 & 0.093 & 0.127 & 0.168 & 0.111 & 0.140 & --- & NS & --- \\
\hline \multicolumn{10}{|l|}{ Female } \\
\hline Age & NS & -0.050 & -0.039 & --- & --- & --- & -- & NS & --- \\
\hline BMI & NS & 0.119 & --- & NS & 0.125 & --- & --- & NS & --- \\
\hline WC & 0.138 & NS & NS & 0.165 & NS & --- & --- & NS & --- \\
\hline SBP & 0.071 & -0.115 & --- & NS & -0.119 & --- & --- & --- & --- \\
\hline DBP & NS & 0.201 & -- & NS & 0.240 & --- & --- & -- & -0.325 \\
\hline FPG & 0.066 & 0.104 & NS & 0.067 & 0.053 & NS & --- & --- & --- \\
\hline HDL-C & NS & 0.109 & 0.040 & NS & --- & --- & NS & --- & --- \\
\hline LDL-C & 0.032 & 0.108 & 0.110 & NS & 0.126 & 0.051 & - & NS & --- \\
\hline TG & 0.162 & 0.119 & 0.153 & 0.127 & 0.090 & 0.107 & NS & --- & --- \\
\hline
\end{tabular}

--- indicates non-inclusion in the regression model, $B M I$ body mass index, WC waist circumference, SBP systolic blood pressure, DBP diastolic blood pressure, FPG fasting plasma glucose, TC total cholesterol, $H D L-C$ high-density lipoprotein cholesterol, $L D L-C$ low-density lipoprotein cholesterol, $T G$ triglyceride, $N S$ non-significant Data are shown as the $\beta$ value when $p$ value $<0.05$

same time, $\mathrm{Hb}$ was found to be associated with BP, FPG, and LDL-C. Compared to WBC and Hb, PLT was least related to MetS, except in the cases of LDL-C and TG. Among the MetS components, it is interesting to note that BMI, LDL-C, and TG were consistently related to all hematogram components for $\mathrm{YO}$ and $\mathrm{OO}$ men. However, only TG had the same consistency for $\mathrm{YO}$ and $\mathrm{OO}$ women.

\section{Discussion}

To our knowledge, the present study is the first to focus on the relationships between hematogram and MetS components among these three elderly groups. WBC and $\mathrm{Hb}$ were correlated with most of the MetS components in men, except for the ODO group. Fewer significant relationships were found among the women, especially those in the OO group. Our data have also shown that, compared to WBC and PLT, Hb was more strongly related to MetS. Finally, among the MetS factors, WC had the highest $r$ value in the multiple regression with WBC in males. At the same time, DBP was the most significant component to be related to $\mathrm{Hb}$, with an average $r$ value of 0.2 .
Because of the complexity of the results, we will discuss the significant findings between MetS and hematogram separately in the following sections so they may be expressed more clearly.

1. The relationship between adiposity and hematogram:

In the present study, we found interesting relationships between BMI, WC, and hematogram. In short, BMI had a negative correlation with hematogram, except in the ODO group. On the contrary, WC was positively correlated with it. Since obesity increases both the size and numbers of adipocytes resulting in increased macrophage infiltration and pro-inflammation status, theoretically the correlations between adiposity and hematogram should be positive [14]. This discrepancy in our study could be readily explained by the fact that lean body mass decreases as the subject gets older. At the same time, abdominal fat increases. Thus, BMI decreases with age, but WC changes in a contrasting direction.

2. The relationship between WBC and MetS components: 
In this study, we found positive correlations between WBC and MetS components in the YO and OO, but not the ODO, groups. Again, these relationships are expected to be due to the effects of proinflammatory cytokines (such as tumor necrosis factor-alpha and interleukin-6), which are secreted by activated macrophages. The macrophage itself is one type of WBC that has been shown to be significantly synthesized in adipose tissue [14]. Several cross-sectional studies have also confirmed our results [20-22]. For example, Tao et al. reported that WBC counts were positively associated with MetS among the young adult (between 20-50 years old) population of Beijing [23]. Generally speaking, this finding is in line with the findings from other major studies. However, no similar report exists for the three elder groups.

3. The relationship between $\mathrm{Hb}$ and MetS components:

$\mathrm{Hb}$ was significantly related to $\mathrm{WBC}$ and MetS components. These relationships have been reported with many different groups [24, 25]. Again, most of them were only limited to adults, rather than specifically the elderly. One of the most important longitudinal studies was done by Laudisio et al., who showed that MetS was associated with higher $\mathrm{Hb}$ levels in a 6-year follow-up period in an older population ( $\geqq 65$ years old) [26]. However, their study placed no particular emphasis on the three different elderly age groups. The role of insulin in stimulating erythropoiesis could be responsible for this relationship. Since insulin resistance is the core of MetS [27], it is not difficult to understand that subjects with MetS would have higher plasma insulin levels to stimulate all stages of erythropoiesis [28].

4. The relationship between PLT and MetS components:

Among the three hematogram components, PLT had the weakest relationships with MetS, except in the cases of LDL-C and TG. PLT is known to play an important role in inflammation due to its effect of inducing the expression of cyclooxygenase- 2 and prostanoids, which accelerate atherothrombosis and cause other features noted in MetS [29-31]. For example, Jesri et al. found that subjects with MetS have higher PLT counts after adjusting for variables such as age and gender [32]. At the same time, Kotani et al. also demonstrated that PLT counts may be biomarkers for MetS among Japanese women [33]. However, in the present study, no correlation between PLT and MetS was found, and this was inconsistent with the aforementioned pathophysiologies. One possible explanation for this discrepancy is that
PLT is seriously influenced by age. Biino et al. showed that PLT reduces by $35 \%$ in men and $25 \%$ in women among the elderly [34]. Hence, the positive correlations between higher PLT and MetS may be masked by a physiological decline in PLT with age.

5. The uniqueness of TG among the other MetS components:

It is interesting to note that among the five MetS components, TG was the only one correlated with all hematogram components. Since TG itself is a risk factor for CVD and T2D, this result is not surprising [35]. This positive finding is also consistent with the findings of other studies. Huang et al. showed that serum TG level was positively correlated with WBC counts in the group of Taipei residents who attended a regular hospital health check program [36]. Cohn et al. also reported that hypertriglyceridemia was strongly related to higher BW and lower levels of insulin sensitivity [37]. The possible mechanism for this relationship could be explained by the work of Feingold et al., who reported that TNF- $\alpha$ and IL-6 stimulate lipolysis and increase the flow of free fatty acids to the liver [38]. These increasing free fatty acids induce hepatic TG synthesis, thus causing hypertriglyceridemia. Contrary to the findings of our study, Purnamasari et al. found that the most important metabolic component was central obesity (56.7 \%), followed by hypertension, hypertriglyceridemia, and hyperglycemia [39]. Our study showed that instead of central obesity, hypertriglyceridemia may be more important for MetS development among ODO groups.

6. The disappearance of most of the relationships in the ODO group:

There is an important and intriguing finding in the present study. In the ODO group, all relationships between MetS and hematogram components, except for TG and LDL, disappeared. Since there are no apparent differences in either the MetS or hematogram components among this group compared to the two younger groups, the effects of aging on these components should not be responsible for this disappearance. The most likely explanation is that the ODO sample was quite small compared to those of the $\mathrm{YO}$ and $\mathrm{OO}$ groups. At the same time, all other significant $r$ values were relatively weak. Therefore, the loss of significance in the ODO group could be rationally explained by combining these two factors.

However, our study is not without its limitations. First, all subjects were enrolled when they received their regular health examinations. Thus, the study members may all have been from a higher socio-economic background 
and consequently might have had lower risk of chronic inflammation diseases than that of the general population. However, the relationships we examined here should not be affected by socio-economic status.

Second, the ODO group was smaller compared to the other two groups, but this also reflects the distribution of the aged subjects in the real world. Third, the core of MetS is insulin resistance, which we were unable to measure due to the lack of plasma insulin levels in our present study. Finally, this is a retrospective study, and further prospective investigations are needed to support the present findings.

\section{Conclusion}

In conclusion, this study found the following: 1 . WBC and $\mathrm{Hb}$ were indeed associated with MetS, even in the $\mathrm{YO}$ and OO groups, regardless of gender; 2. Among the three hematogram components, $\mathrm{Hb}$ had the strongest and PLT the weakest correlation with MetS; and 3. TG is not the only component that had relatively high $r$ values, and it is related to all the hematogram components.

\section{Abbreviations}

MetS: metabolic syndrome; YO: young old; OO: old old; ODO: oldest old; WBC: white blood cell; Hb: hemoglobin; PLT: platelet; BMl: body mass index; SBP: systolic blood pressure; DBP: diastolic blood pressure; TG: triglycerides; HDL: high-density lipoprotein cholesterol; LDL: low-density lipoprotein cholesterol.

\section{Competing interests}

The authors declare that they have no competing interests.

\section{Authors' contributions}

YLC, CHH and HWC designed the design and worked together to complete the manuscript. JSC, JBC and TJC performed the statistical analysis and interpreted the results. DP, CZW and CLH discussed the results and how to write the manuscript. All authors read and approved the final manuscript.

\section{Acknowledgments}

We declare that all authors listed have actively participated in the study and have met the requirements of authorship. All authors have read and approved the final version of the manuscript. The authors sincerely thank M.J. Life Clinic in Taiwan for providing the anonymous data for the present study.

\section{Author details \\ ${ }^{1}$ Division of Endocrinology and Metabolism, Department of Internal Medicine, Tri-Service General Hospital, National Defense Medical Center, Taipei, Taiwan. ${ }^{2}$ Division of Nephrology, Department of Internal Medicine, Tri-Service General Hospital, National Defense Medical Center, Taipei, Taiwan, R.O.C.. ' ${ }^{3}$ Department of Pathology, Division of Clinical Pathology, Tri-Service General Hospital, National Defense Medical Center, Taipei, Taiwan, R.O.C.. ${ }^{4}$ Division of Endocrinology, Department of Internal Medicine, Shuang-Ho Hospital, School of Medicine, College of Medicine, Taipei Medical University, Taipei, Taiwan, R.O.C.. ${ }^{5}$ Department of Internal Medicine, Cardinal Tien Hospital, School of Medicine, Fu-Jen Catholic University, New Taipei City, Taiwan. ${ }^{6}$ Department of Pathology, Cardinal Tien Hospital, School of Medicine, Fu-Jen Catholic University, New Taipei City, Taiwan.}

Received: 26 August 2015 Accepted: 4 January 2016

Published online: 13 January 2016

\section{References}

1. Ríos-Hoyo A, Cortés MJ, Ríos-Ontiveros H, Meaney E, Ceballos G, Gutiérrez-Salmeán G. Obesity, metabolic syndrome, and dietary therapeutical approaches with a special focus on nutraceuticals (polyphenols): a mini-review. Int J Vitam Nutr Res. 2014;84(3-4):113-23.
2. Palaniappan $L$, Carnethon M, Fortmann SP. Association between microalbuminuria and the metabolic syndrome: NHANES III. Am J Hypertens. 2003;16:952-8.

3. González M, del Mar Bibiloni M, Pons A, Llompart I, Tur JA. Inflammatory markers and metabolic syndrome among adolescents. Eur J Clin Nutr. 2012:66:1141-5.

4. Odagiri K, Uehara A, Mizuta I, Yamamoto M, Kurata C. Longitudinal study on white blood cell count and the incidence of metabolic syndrome. Intern Med. 2011;50:2491-8.

5. Nakanishi N, Suzuki K, Tatara K. White blood cell count and clustered features of metabolic syndrome in Japanese male office workers. Occup Med (Lond). 2002;52:213-8.

6. Lee YJ, Shin YH, Kim JK, Shim JY, Kang DR, Lee HR. Metabolic syndrome and its association with white blood cell count in children and adolescents in Korea: The 2005 Korean National Health and Nutrition Examination Survey. Nutr Metab Cardiovasc Dis. 2010;20:165-72.

7. Oda E, Kawai R. The prevalence of metabolic syndrome and diabetes increases through the quartiles of white blood cell count in Japanese men and women. Intern Med. 2009:48:1127-34.

8. Piédrola G, Novo E, Escobar F, García-Robles R. White blood cell count and insulin resistance in patients with coronary artery disease. Annales D'endocrinologie. 2001;62:7-10.

9. Nagasawa N, Tamakoshi K, Yatsuya H, Hori Y, Ishikawa M, Murata C, et al. Association of white blood cell count and clustered components of metabolic syndrome in Japanese men. Circ J. 2004;68:892-7.

10. Chen YL, Hsu CH, Hseih CH, Wang K, Wu CZ, Wang CY, et al. Association between platelet count and components of metabolic syndrome in geriatric Taiwanese women. Int J Gerontol. 2012;6(3):201-5.

11. Shimakawa T, Bild DE. Relationship between hemoglobin and cardiovascular risk factors in young adults. J Clin Epidemiol. 1993;46:1257-66.

12. WS Shim, HJ Kim, ES Kang, CW Ahn, SK Lim, HC Lee, et al. The association of total and differential white blood cell count with metabolic syndrome in type 2 patients. Diabetes Res Clin Pract. 2006;73:284-291.

13. Mokdad AH, Bowman BA, Ford ES, Vinicor F, Marks JS, Koplan JP. The continuing epidemics of obesity and diabetes in the United States. JAMA. 2001;286(10):1195-200.

14. Després JP. Is visceral obesity the cause of the metabolic syndrome? Ann Med. 2006:38(1):52-63.

15. Hiramatsu M, Ishida M, Tonozuka Y, Mikami H, Yamanari T, Momoki N, et al. Application of peritoneal dialysis in elderly patients by classifying the age into young-old, old, and oldest-old. Contrib Nephrol. 2012;177:48-56.

16. Yoshimura K, Yamada M, Kajiwara Y, Nishiguchi S, Aoyama T. Relationship between depression and risk of malnutrition among community-dwelling young-old and old-old elderly people. Aging Ment Health. 2013;17:456-60.

17. Report of a Joint Rural Health Advisory Committee and State Community Health Services Advisory Committee Work Group. Creating healthy communities for an aging population. Minnesota: Community and Family Health Division, Office of Rural Health and Primary Care and Office of Public Health Practice; 2006.

18. Alberti KG, Eckel RH, Grundy SM, Zimmet PZ, Cleeman II, Donato KA, et al. Harmonizing the metabolic syndrome: a joint interim statement of the International Diabetes Federation Task Force on Epidemiology and Prevention; National Heart, Lung, and Blood Institute; American Heart Association; World Heart Federation; International Atherosclerosis Society; and International Association for the Study of Obesity. Circulation. 2009;120(16):1640-5.

19. Health Promotion Administration, M.o.H.a.W., R.O.C. (Taiwan). Available from: http://www.hpa.gov.tw/BHPNet/Web/HealthTopic/TopicArticle.aspx?No= 200712250123\&parentid=200712250023. Accessed 25 December 2007.

20. Lohsoonthorn V, Jiamjarasrungsi W, Williams MA. Association of hematological parameters with clustered components of metabolic syndrome among professional and office workers in Bangkok, Thailand. Diabetes Metab Syndr. 2007:1(3):143-9.

21. Fadini GP, Marcuzzo G, Marescotti MC, de Kreutzenberg SV, Avogaro A. Elevated white blood cell count is associated with prevalence and development of the metabolic syndrome and its components in the general population. Acta Diabetol. 2012;49(6):445-51.

22. Oda E. High-sensitivity C-reactive protein and white blood cell count equally predict development of the metabolic syndrome in a Japanese health screening population. Acta Diabetol. 2013;50(4):633-8. 
23. Tao LX, Li X, Zhu HP, Huo D, Zhou T, Pan L, et al. Association of hematological parameters with metabolic syndrome in Beijing adult population: a longitudinal study. Endocrine. 2014;46(3):485-95.

24. Hanley AJG, Retnakaran R, Qi Y, Gerstein HC, Perkins B, Raboud J, et al. Association of hematological parameters with insulin resistance and b-cell dysfunction in nondiabetic subjects. Endocrine Care. 2009;94:3824-32.

25. Wang LM, Myers Jr MG, Sun KJ, Aaronson SA, White M, Pierce JH. IRS-1: Essential for insulin and II-4 stimulated mitogenesis in hematopoietic cells. Sience. 1993;261:1591-4.

26. Laudisio A, Bandinelli S, Gemma A, Ferrucci L, Antonelli Incalzi R. Metabolic syndrome and hemoglobin levels in elderly adults: the Invecchiare in Chianti Study. J Am Geriatr Soc. 2013;61(6):963-8.

27. Hanley AJG, Wagenknecht LE, D'Agostino RB, et al. Identification of subjects with insulin resistance and B-cell dysfunction using alternative definitions of the metabolic syndrome. Diabetes. 2003;52(11):2740-7.

28. Barbieri M, Ragno E, Benvenuti E, Zito GA, Corsi A, Ferrucci L, et al. New aspects of the insulin resistance syndrome: impact on haematological parameters. Diabetologia. 2001;44:1232-7.

29. Pasarica M, Sereda OR, Redman LM, Albarado DC, Hymel DT, Roan LE, et al. Reduced adipose tissue oxygenation in human obesity: evidence for rarefaction, macrophage chemotaxis, and inflammation without an angiogenic response. Diabetes. 2009;58:718-25.

30. Regazzetti C, Peraldi P, Gremeaux T, Najem-Lendom R, Ben-Sahra I, Cormont $M$, et al. Hypoxia decreases insulin signaling pathways in adipocytes. Diabetes. 2009;58:95-103.

31. Dovizio M, Alberti S, Guillem-Llobat P, Patrignani P. Role of platelets in inflammation and cancer: novel therapeutic strategies. Basic Clin Pharmacol Toxicol. 2014;114:118-27.

32. Jesri A, Okonofua EC, Egan BM. Platelet and white blood cell counts are elevated in patients with the metabolic syndrome. J Clin Hypertens (Greenwich). 2005;7:705-11.

33. Kotani K, Sakane N, Saiga K, Mu H, Kurozawa Y. Clustered components of the metabolic syndrome and platelet counts in Japanese females. Clin Chem Lab Med. 2007:45:376-9.

34. Vega GL, Barlow CE, Grundy SM, Leonard D, DeFina LF. Triglyceride-to-highdensity-lipoprotein-cholesterol ratio is an index of heart disease mortality and of incidence of type 2 diabetes mellitus in men. J Investig Med. 2014;62(2):345-9.

35. Biino G, Santimone I, Minelli C, Sorice R, Frongia B, Traglia M, et al. Age- and Sex-related variations in platelet count in Italy: a proposal of reference ranges based on 40987 subjects' data. PLoS ONE. 2013;8(1):e54289.

36. Huang ZS, Chien KL, Yang CY, Tsai KS, Wang CH. Peripheral differential leukocyte counts in humans vary with hyperlipidemia, smoking, and body mass index. Lipids. 2001;36(3):237-45.

37. Cohn JS, Patterson BW, Uffelman KD, Davignon J, Steiner G. Rate of production of plasma and very-low-density lipoprotein (VLDL) apolipoprotein C-III is strongly related to the concentration and level of production of VLDL triglyceride in male subjects with different body weights and levels of insulin sensitivity. J Clin Endocrinol Metab. 2004;89(8):3949-55.

38. Feingold KR, Doerrler W, Dinarello CA, Fiers W, Grunfeld C. Stimulation of lipolysis in cultured fat cells by tumor necrosis factor, interleukin-1, and the interferons is blocked by inhibition of prostaglandin synthesis. Endocrinology. 1992;130(1):10-6

39. Purnamasari D, Soegondo S, Oemardi M, Gumiwang I. Insulin resistance profile among siblings of type 2 diabetes mellitus (preliminary study). Acta Med Indones. 2010;42(4):204-8.

\section{Submit your next manuscript to BioMed Central and we will help you at every step:}

- We accept pre-submission inquiries

- Our selector tool helps you to find the most relevant journal

- We provide round the clock customer support

- Convenient online submission

- Thorough peer review

- Inclusion in PubMed and all major indexing services

- Maximum visibility for your research

Submit your manuscript at www.biomedcentral.com/submit
Biomed Central 